\title{
FRACTURE LOAD OF ALL-CERAMIC CROWNS AFTER TWO DIFFERENT CONDITIONING TECHNIQUES
}

\author{
Shaimaa Ahmed Abo El-Farag Ibraheim *
}

\begin{abstract}
Purpose: This study investigated influence of two conditioning methods and two luting cements on the fracture load of all-ceramic crowns.

Materials and methods: A total of thirty-two CAD-CAM all-ceramic crowns, (Vita Mark II) were constructed on human upper premolars indicated for extraction and collected from department of oral surgery, faculty of dentistry, Mansoura University. The intaglio surfaces of 16 crowns were treated using acid $(4.9 \% \mathrm{HF})$ with silane application. The other 16 crowns were conditioned using Monobond Etch \& prime in one step. Each group divided into 2 subgroups ( $n=8)$ according to used type of luting cements. Self adhesive resin cement (Rely X U200) or multistep adhesive resin cement (Mutilinik Automix) were used for crowns cementation to appropriate teeth. Crowns were kept in water for 3 months but after cementations by one hour. Universal testing machine was used to record the fracture load for crowns $(\mathrm{N})$.
\end{abstract}

Results: Means fracture load of groups luted with multistep adhesive resin cement were significantly higher than means fracture load of test groups luted using self adhesive resin cement regardless of conditioning techniques used $(P<0.05)$. Means fracture loads of other test groups were not statistically significant $(P>0.05)$.

Conclusions: Two techniques used for conditioning of Vita Mark II crowns did not affect significantly fracture load of these crowns. Multilink adhesive resin cement improved fracture loads of Vita Mark II crowns compared to RelyX U200.

KEYWORDS: All-ceramic crowns, ceramic conditioning, luting cement

\section{INTRODUCTION}

The development in the physical properties and fabrication techniques of esthetic materials as all-ceramics, facilitates the construction of posterior all-ceramic restorations to be faced with highly demands of patients who prefer natural like appearance of esthetic restorations..$^{1-5}$ Moreover fabrication of all-ceramic crowns using computeraided design/computer-aided manufacturing $(\mathrm{CAD} /$ CAM) technology, milled and cemented intraorally in single visit thus decreasing treatment time, associated with accurate adaptation, good esthetics,

\footnotetext{
* Lecturer at Department of Fixed Prosthodontics, Faculty of Dentistry, Mansoura University, Egypt
} 
and economic benefits for the patient. ${ }^{\mathbf{2}, \mathbf{6}}$ Resin bonded all-ceramic restorations offer the ability to stabilize hard tissues, preserve the residual tooth structure with improving the fracture resistance. ${ }^{7,8}$ However the main causes of failure of all-ceramic crowns reported in several studies were catastrophic fractures of the crowns. ${ }^{3,9}$

A durable bond at restorations/luting cement/ tooth structure is a unique step for long term success of these restorations ${ }^{10}$, therefore different types of materials and methods have been introduced for modifications in restorations surfaces to upgrade resin bonding to silicate ceramic.,112 These treatments including: mechanical method in which aluminum oxide $\left(\mathrm{Al}_{2} \mathrm{O}_{3}\right)$ particles were used for airborne-particle abrasion ${ }^{12,13}$, and etching using hydrofluoric acid (HF) ${ }^{13}$ which cause effective changes in the fitting surface of all ceramic crowns for both mechanical retention and chemical adhesion. ${ }^{12}$ Implementation of a silane coupling agent is usually performed after roughening of ceramic surfaces for improvement of chemical bonding to silica-based ceramics. ${ }^{13-15}$ Conventional silane coupling agent containing 3-methacryloxypropyltrimethoxysilane (MPS) has been used since over 20 years to promote chemical bonding to silica-based ceramics., ${ }^{1,12,15,16}$ Recently a newly developed single stage Etch \& Prime (Monobond E\&P) introduced to merge HF acid etching and primer application in one step .

The preferable type of dental material used for cementation of all-ceramic restorations is adhesive resin cements. ${ }^{17-19}$ However the complicated bonding procedures challenge the routine use of these cements ${ }^{20,21}$, therefore the newly developed type of cement called self-adhesive resin cements have been introduced into the field of dentistry and spread in dental market to facilitate the bonding procedures of indirect restorations..$^{22-24}$ The use of these types of luting materials is complemented by a one clinical phase in which the synchronous demineralization/infiltration of the bonding substrate is expected to occur ${ }^{25,26}$ so, they need no pretreatments of tooth structure using either conditioning or priming agents. ${ }^{24,27}$ Therefore the aim of this in vitro study was to evaluate 1 . Effect of intaglio surface conditioning of Vita Mark II allceramic crowns using Monobond Etch \&Prime in one step compared to HF acid etching and silane application, 2. Influence of using of self-adhesive resin cement and multistep resin cement on the fracture load of Vita Mark II crowns. Null hypothesis of current study was that the fracture load of allceramic crowns would not be affected by either different ceramic primers or different adhesive resin cements.

\section{MATERIALS AND METHODS}

Totally used 32 human upper premolars free from caries and crack were collected from oral surgery department, faculty of dentistry, Mansoura University. Any calculus deposits or remnants of soft tissues were cleaned from selected premolars, then stored in $0.1 \%$ thymol disinfectant solution. Autopolymerized acrylic resin was used for fixation of all teeth inside metallic ring to be ready for preparation which performed with diamond burs fixed in a custom made paralleling device. The standardized preparation criteria were used for teeth preparation as the following 11,28,29: tapering of axial walls about 6-degree, shoulder finish line $(1.2 \mathrm{~mm})$ prepared occlusal to the CEJ by 0.5 $\mathrm{mm}$, occlusal reduction was $2 \mathrm{~mm}$ and occlusogingival height was $5 \mathrm{~mm}$. After that, CAD-CAM technology (Ceramill motion 2 (5X) CAD/CAM system, Amann Girrbach, Germany) was used for wet milling of Vita Mark II crowns: a conventional feldspathic ceramic with fine grain size particles avaliable in machinable blocks with different sizes (Vita, Bad Sackingen, Germany). This system is composed of the ceramill map 400 scanner ceramill mind software and ceramill motion 2 (5X) milling unit. The recommended firing program was used for over-glazing of crowns according to the manufacturer instructions. 


\section{Bonding procedures:}

Intaglio surfaces of main group $(H) \quad(n=16)$ crowns were treated by etching using acid called HF $4.9 \%$ etching gel (IPS ceramic etching gel, Ivoclar Vivadent, Schaan, Liechtenstein) for one minute. Treated surfaces were cleaned using water spray for $60 \mathrm{~s}$, and then ultrasonically in $99 \%$ isopropanol, an oil-free compressed air was used for dryness. Conventional silane was applied, (SI), (Monobond S, 3-methacryloxyprophyltrimethoxysilane in ethanol, acetic acid, Ivoclar Vivadent, Schaan, Liechtenstein).

The intaglio surfaces of main group $(\mathrm{E})(\mathrm{n}=16)$ crowns were conditioned using Monobond Etch \& Prime (Monobond Etch \& Prime, Ivoclar Vivadent, Schaan, Liechtenstein) for one minute according to the manufacture instructions as follow, A microbrush was used for applying the Monobond Etch and Prime to cover the intaglio surface of each crown for one minute then, rinsing with air-water spray and drying with oil free compressed air for one minute.

Prepared tooth surfaces were thoroughly cleaned with a prophy cup with fine flour pumice to ensure removal of scanning powder and liquid. Each main group classified into 2 equal subgroups $(n=8)$ according to type of cementation material to be used as follow:

1. Multilink Automix (M); dual-polymerizing, universal, two past adhesive resin cement, it is composed of dimethacrylate and HEMA. (Ivoclar Vivadent). The adherent tooth surface was covered by mix of Multilink Primer A+B (1:1) and applied for 15 seconds then dried with oil free air. The same amounts of the luting cement were extruded, mixed for $20 \mathrm{sec}$. then the homogenous cement was inserted into the crowns intaglio surface.

2. RelyX U200 (R); dual-polymerizing, self adhesive resin cement, composed of phosphoric acid monomer and methacrylate monomers. (RelyX
U200 in double-push clicker, 3M ESPE) was used for cementation according to manufacturer instructions. Equal amounts of the cement were extruded from its clicker by double-push then the two pastes were blended in a 1:1 ratio for 20 seconds. Luting material was inserted directly onto the fitting surfaces of crowns. Each crown was fixed on its particular premolar. A static load of $40 \mathrm{~N}$ was applied on each specimen for 5 minutes. After cementation, any excess of luting material surrounding crown margin was eliminated rapidly. A total of four test groups were resulted as follow: $\mathrm{MH}, \mathrm{RH}, \mathrm{ME}$ and $\mathrm{RE}$.

All luted crowns were stored in water bath at $37^{\circ} \mathrm{C}$ for 3 months (One hour after cementation). A stainless steel bar with a 4-mm diameter ball endmounted in a screw-driven universal testing machine (Z010; Zwick, Ulm, Germany) used to apply compressive load along the long axis of each specimen at a cross-head speed of $1 \mathrm{~mm} / \mathrm{min}$ until fracture..$^{11,28-30}$ Compressive load required to cause fracture $(\mathrm{N})$ for each specimen was recorded. Four cylindrical shape discs were milled from machinable block of Vita Mark II to examine surface etching characterization using a Scanning electron microscope (SEM) (JEOL JSM $6510 \mathrm{lv}$, Japan) at different magnifications. (Fig.1) Two-way analysis of variance
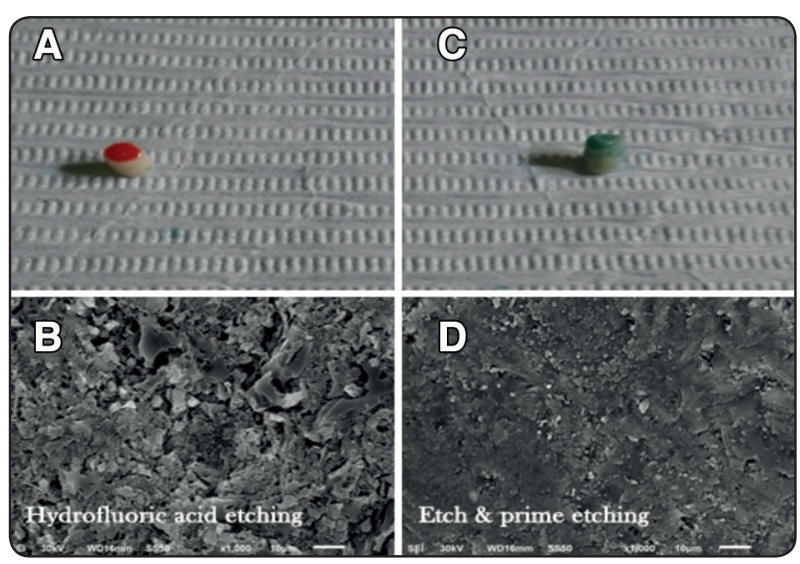

Fig. (1) Showing: (A) cylindrical disc of Vita Mark II treated with Hydroflouric acid, (B) SEM image after HF acid etching, (C) cylindrical disc treated with Etch \& prime, (D) SEM image after Etch \& prime etching. 
(ANOVA) followed by serial 1-way (ANOVA)s at each level of the study and Tukey'honestly significant difference (HSD) test at significance level of 0.05 were used for statistical analysis of the data.

\section{RESULTS}

Means fracture loads of all groups were compared with a 2-factor ANOVA model, including the following factors: ceramic primers, luting cements and their interactions. The overall ANOVA F-test was highly significant $(P<.0001)$, indicating differences in mean fracture loads across at least one of the factors. Luting cements $(P=.003)$ factor was significant. However intaglio surface conditiong factor $(P=.724)$ and the interaction between intaglio surface conditiong and luting cements were not significant $(P=.986)$. Serial 1-way (ANOVA) $\mathrm{s}$ were conducted at each level of the study. Means, standard deviation, minimum and maximum fracture loads of all groups are presented in Table (1). Post Hoc analysis with the Tukey HSD test showed that mean fracture load of group ME (1203.4 \pm 90.2) was significantly higher than mean fracture load of

TABLE (1) Static fracture load of all test groups with means, standard deviations, minimum and maximum in $\mathrm{N}$ and $P$ values, (Tukey test at $P=.05$ ).

\begin{tabular}{|c|c|c|c|c|}
\hline \multirow{2}{*}{ Groups } & \multicolumn{2}{|c|}{$\begin{array}{l}\text { Monobond E\&P } \\
\text { (E) }\end{array}$} & $\mathrm{HF} \&$ silane $(\mathrm{H})$ & \multirow[t]{2}{*}{$P$ values } \\
\hline & $\begin{array}{l}\text { Me an } \\
\pm \mathrm{SD}\end{array}$ & $\begin{array}{l}\text { Min. } \\
\text { Max. }\end{array}$ & $\begin{array}{lll}\text { Mean } & \pm & \text { Min. } \\
\text { SD } & \text { Max. }\end{array}$ & \\
\hline M & $\begin{array}{l}1203.4 \\
\pm 90.2\end{array}$ & $\begin{array}{l}976.3 \\
1290.5\end{array}$ & $\begin{array}{ll}1099.3 \pm & 973.4 \\
82.8 & 1120.6\end{array}$ & .79 \\
\hline $\mathrm{R}$ & $\begin{array}{l}1054.3 \\
\pm 64.7\end{array}$ & $\begin{array}{l}968 \\
1102.8\end{array}$ & $\begin{array}{lll}1035.7 & \pm & 981.8 \\
72 & & 1179\end{array}$ & .85 \\
\hline
\end{tabular}

M = Multilinik Automix

$R=\operatorname{Rely} U 200$ self adhesive resin cement

E = Monobond Etch\&Prime

$H=H F$ acid etching and silane groups $\mathrm{RE}(1054.3 \pm 64.7 \mathrm{~N}, \mathrm{P}=.018)$ and group $\mathrm{RH}$ $(1035.7 \pm 72 \mathrm{~N}, \mathrm{P}=.009)$. However, there was no statistically significant difference $(\mathrm{P}>0.05)$ between means fracture loads of other test groups as follow; group $\mathrm{ME}$ and $\mathrm{MH},(\mathrm{P}=0.79)$ and group $\mathrm{RE}$ and $\mathrm{RH}(\mathrm{P}=0.85)$.

\section{DISCUSSION}

The improvement of all-ceramic crowns in term of retention and/or fracture resistance is considered the ideal goal for improving bonding of these crowns to restorative material and to tooth structure. ${ }^{21}$ Therefore this in vitro study invistigated fracture load of CAD-CAM all-ceramic crowns cemented using two resin cements after different pretreatment methods of intaglio surfaces of crowns. The fracture resistance of all-ceramic crowns affected by several factors including: microstructure of ceramic material and its composition ${ }^{5,28}$, the technique of its fabrication ${ }^{11,28,31}$, luting method ${ }^{2,28,29}$, conditions of storage and type of the fatigue test used. ${ }^{2,5,28,31}$ In the present study the criteria of clinically established preparation was followed for ideal natural teeth preparation to receive all-ceramic crowns., ${ }^{2,11,28,30}$ The technique of cementation was performed as the clinical steps to provide a close emulation of clinically applied conditions. . $^{2,13,28}$

Test groups were stored in water for 3 months, because all extra-orally performed studies should simulate the clinical conditions. The mean maximum posterior forces of mastication differ from $200 \mathrm{~N}$ to $540 \mathrm{~N} .^{11,28,30}$ Mean fracture loads of allceramic crowns (Vita mark II) reported in this work were higher than reported mean maximum masticatory forces. Subsequently it may be imagined that both Monobond Etch and Prime and HF acid etching with silane plus the two luting cements used were effective to enhance bonding at crown/cement/ prepared teeth assembly. Consequently, the specimens reacted aganist the applied compressive load as single unit. 
Moreover means fracture load of test groups in this study were higher than fracture loads of test groups reported in other studies. ${ }^{28,}{ }^{29}$ This difference could be attributed to many factors such as, difference in the test conditions of these studies ${ }^{\mathbf{2 8}}$, ${ }^{29}$ where test groups were exposed to cyclic loading fatigue in masticatory simulator for 600000 cycles before applying the compressive load till fracture, compared to storage in water only for 3 months in this study. Other factors could be difference in the mechanical properties of ceramic materials, luting agents and luting techniques used for cementation.

The null hypothesis of this study should be partialy rejected because the Monobond Etch \& Prime and conventional silane with HF acid etching did not affect the fracture load of Vita Mark II crowns. This could be related to the fact that, fitting surfaces of the crowns treated with silane application after etching with HF acid, this etching protocol increased surface energy of the ceramic ${ }^{12}$, created microsurface pores in the intaglio surface to ensure micromechanical interlocking with the adhesive resin cement used..$^{12,13,15}$

The most frequently used acid is the hydrofluoric acid, which reacts with ceramic when applied onto its surface and reacts with the silica matrix creating silicon tetrafluoride and molecules of water that are released. The silicon tetrafluoride reacts with other molecules of hydrofluoric acid forming a soluble complex ion, hexafluourosilicate hydrogen ions. Further on, the hydrogen ions react with the hexafluorosilicate complex forming a fluorosilicic acid that can be rinsed off. By dissolving and removing the surface layer of the glassy matrix containing silica $\left(\mathrm{SiO}_{2}\right)$, silicates $\left(\mathrm{SiO}_{4}\right)$ and leucite crystals $\left(\mathrm{K}_{2} \mathrm{O} \bullet \mathrm{Al}_{2} \mathrm{O}_{3} \bullet 4 \mathrm{SiO}_{2}\right)$, the surface becomes porous with a pore size of $3-4 \mu \mathrm{m} \cdot{ }^{32}$ Conventional silane coupling agent contains 3-methacryloxypropyltrimethoxysilane (MPS) pre-hydrolysed and diluted in ethanol-water solution, Ca. 1-2\%, pH 4-5 adjusted with acetic acid ${ }^{1,12-16}$, its effective action is silani- zation of silica ceramics to ensure chemical bonding at ceramic/cement interface. ${ }^{12,16}$ In addition to its role for adhesion chemically, other study showed that silanes agent reduce the contact angle and improve the spread of used resin material for cementation to cover the entire surface of ceramic crowns. ${ }^{33}$

Many other factors should be taken into consideration during work, these factors as that, the mechanical criteria of glass ceramics can be deteriorated by the etching with $\mathrm{HF}$ acid ${ }^{34,35-37}$, and it is also considered as a highly toxic dangerous acidic material. ${ }^{38}$ Other study investigated the cause of its high toxicity and found that this acid has greater ability for necrosis of soft tissues and bones over exposure for long periods of time..$^{38}$ Regarding to HF acid etching, these two harmful effects are considered time- and concentration-dependents. ${ }^{37-40}$

Newly developed type of self-etching ceramic primer (ME\&P; Monobond Etch \& Prime, Ivoclar Vivadent; Schaan, Liechtenstein) has been introduced into dental field as a simple substitution to the traditional method of etching for improving of the glass-ceramic surfaces by using HF acid etching followed by silane application. Ceramic primer is considered a basic composition of ME\&P which formed of ammonium polyfluoride, a silane system based on trimethoxypropyl methacrylate, solvents (water and alcohols), and some additives like pigment (responsible for its green color), all these components called all-in-one system (one-step etching technique). So, this abbreviated, simple technique for adhesion requires short period of working time, might prohibit the weakening effect of glass-ceramics (mild etching-less aggressive), and reduces possibility of dangerous effect. ${ }^{41}$

Creation of a rough ceramic surface is considered a basic mechanism of action of the ME\&P that depends on the reaction of ammonium polyfluoride with the clean ceramic surface, this action provide large surface area and stimulates micromechanical interlocking. Using of both water rinsing and ultra- 
sonic bath, remove the products released from the reaction, and Ammonium polyfluoride while dryness with oil free air causes the evaporation of solvents, therefore, the second step to adhesion begins. Interaction with used resin cement was stimulated by formation of a chemically active thin layer resulted from reaction between the silane content (trimethoxypropyl metacrylate) and the surface of glass-ceramic. ${ }^{41}$

Many research works compared between the bond strength of surfaces treated with Monobond E\&P and other surfaces etched with $\mathrm{HF}$ acid + silane application, the findings of this comparison showed identical effects to those from the well-established protocol for etching glass-ceramics. ${ }^{11,42-44}$

The mode of surface characterization in this study was investigated using the SEM. It was observed that surfaces which conditioned by ME\&P showed a less irregular characteristics than the other surfaces treated with HF acid, this observation was in agreement with studies performed by Scherer et al. ${ }^{41}$ and Siqueira et al.$^{42}$ who proved that the ME\&P has less aggressive effect on the glassy matrix than the other effect showed by HF acid etching. In spite of this observation, they concluded that the irregularities created by ME\&P was acceptable and sufficient to obtain proper adhesion mechanism.

The findings of the current work explained that, there was no significant effect on the fracture load of all-ceramic crowns when both Monobond Etch \&Prime and conventional silane with HF acid etching were used, these findings were disagreed with the other research works which found that the hydrofluoric acid plus silane application showed higher mean bond strength than Monobond Etch \& Prime for both lithium disilicate ceramic (IPS e.max CAD) and feldspathic ceramic (VITA Mark II), also treatment of the bonding surface of glass-ceramic restorations using acid etching is considered as the most effective treatment method that provides a reliable bond with composite cement. ${ }^{32,45}$
In this study two different types of resin cements were used, one of them is multistep adhesive resin cement (Multilink Automix) as these materials are time consuming for application, technique sensitive and require multiple, complicated bonding procedures. ${ }^{46,47-49}$ Although Multilink does not contain adhesive phosphate monomer, its dimethacrylate monomers and HEMA seemed to improve its mechanical properties, which may be responsible for high bond strength results. Also, self-adhesive resin cement (Rely X) was used in this in vitro study, as its bonding mechanism is based on demineralization and infiltration of dentin simultaneously at one time to form a hybrid layer through multifunctional monomers and acid groups included in their chemical composition..$^{\mathbf{5 0 - 5 3}}$ Furthermore RelyXUnicem contains multifunctional acid methacrylates, so this group could improve bonding to ceramics. ${ }^{10,17}$ Several in vitro studies reported that, bond strength of RelyX Unicem to glass ceramic after HF acid etching and silanation was comparable to that of other luting cements. ${ }^{19-21}$

\section{CONCLUSIONS}

Within the conditions of the current study, the following conclusions can be outlined:

1. Fracture load of Vita Mark II all-ceramic crowns wasn't affected by using of Monobond Etch \& Prime and conventional silane with HF acid etching.

2. Multilink adhesive resin cement improved fracture loads of Vita Mark II crowns compared to RelyX U200.

\section{REFERENCES}

1. Peumans M, Hikita K, De Munck J, Van Landuyt K, Poitevin A, Lambrechts P, Van Meerbeek B. Effects of ceramic surface treatments on the bond strength of an adhesive luting agent to CAD-CAM ceramic. J Dent 2007; 35:282-288.

2. Nueesch R, Conejo J, Mante F, Fischer J, Märtin S, Rohr N, Blatz MB. Loading capacity of CAD/CAM- Fabricated anterior feldspathic ceramic crowns bonded to one-piece zirconia implants with different cements. Clin Oral Impl Res. 2019;00: 1-9. 
3. Thompson VP, Rekow DE. Dental ceramics and the molar crown testing ground. J Appl Oral Sci 2004; 12: 26-36.

4. Etman M K, Woolford M J. Three-year clinical evaluation of two ceramic crown systems: A preliminary study. J Prosthet Dent 2010; 103:80-90.

5. Clausen $\mathrm{O}$, Abou Tara M, Kern M. Dynamic fatigue and fracture resistance of non-retentive all-ceramic fullcoverage molar restorations. Influence of ceramic material and preparation design. Dent Mater, 2010:26:533-538.

6. Riedel C, Wendler M, Belli R, Petschelt A, Lohbauer U. In vitro lifetime of zirconium dioxide-based crowns veneered using Rapid Layer Technology. Eur J Oral Sci 2019; 00: 1-8.

7. Blair KF, Koeppen RG, Schwartz RS, Davis RD. Microleakage associated with resin composite-cemented, cast glass ceramic restoration. Int J Prosthodont 1993; 6:579-584.

8. Fasbinder D J. Clinical performance of chairside CAD/ CAM restorations. J Am Dent Assoc 2006; 137:22S-31S.

9. Bona AD, Kelly J R. The clinical success of all-ceramic restorations. J Am Dent Assoc 2008; 139:8S-13S.

10. Dimitriadi M, Eliades G. Reactivity of dental silane coupling agents. Dent Mater. 2017; 33: e26.

11. Rodríguez JLR, Barquero JAP, Angulo EG, Font AF, Salvador JLB. Bonding to silicate ceramics: Conventional technique compared with a simplified technique. J Clin Exp Dent. 2017; 9:384-386.

12. Bona AD, Borba M, Benetti P, Pecho OE, Alessandretti R, Mosele JC, Mores RT. Adhesion to Dental Ceramics. Curr Oral Health Rep 2014; 1: 232-238.

13. Santos`GC Jr, Santos MJ, Rizkalla AS. Adhesive cementation of etchable ceramic esthetic restorations. J Can Dent Assoc 2009; 75:379-384

14. Matinlinna JP, Lung CYK, Tsoi JKH. Silane adhesion mechanism in dental applications and surface treatments: A review. Dent mater. 2018; 34: 13-28.

15. Rüttermann S, Fries L, Raab WH, Janda R. The effect of different bonding techniques on ceramic/resin shear bond strength. J Adhes Dent 2008; 10:197-203.

16. Kern M. Resin bonding to oxide ceramics for dental restorations. J Adhes Sci Technol, 2009; 23:1097-1111.

17. Holderegger C, Sailer I, Schuhmacher C, Schläpfer R, Hämmerle C, Fischer J. Shear bond strength of resin cements to human dentin. Dent Mater 2008; 24:944-950.

18. Chaves CAL, de Melo RM, Passos SP, Camargo FP, Bottino MA, Balducci I. Bond strength durability of self-etching adhesives and resin cements to dentin. J Appl Oral Sci 2009; 17:155-160.
19. Zhang C, Degrange M. Shear bond strengths of selfadhesive luting resins fixing dentine to different restorative materials. J Biomater Sci Polym Ed 2010; 21:593-608.

20. Piwowarczyk A, Lauer HC, Sorensen JA. In vitro shear bond strength of cementing agents to fixed prosthodontic restorative materials. J Prosthet Dent 2004; 92:265-273.

21. Capa N, Ozkurt Z, Canpolat C, Kazazoglu E. Shear bond strength of luting agents to fixed prosthodontic restorative core materials. Aust Dent J 2009; 54:334-340.

22. Behr M, Rosentritt M, Wimmer J, Lang R, Kolbeck C, Bürgers R, Handel G. Self-adhesive resin cement versus zinc phosphate luting material: a prospective clinical trial begun 2003. Dent Mater 2009; 25:601-604.

23. Saskalauskaite E, Tam LE, McComb D. Flexural strength, elastic modulus, and $\mathrm{pH}$ profile of self-etch resin luting cements. J Prosthodont 2008; 17:262-268.

24. Brunzel S, Yang B, Wolfart S, Kern M. Tensile Bond Strength of a so-called self-adhesive luting resin cement to dentin. J Adhes Dent 2010; 12: 143-150

25. Radovic I, Monticelli F, Goracci C, Vulicevic ZR, Ferrari M. Self-adhesive resin cements: a literature review. J Adhes Dent 2008; 10:251-258.

26. Vrochari AD, Eliades G, Hellwig E, Wrbas KT. Curing efficiency of four self-etching, self-adhesive resin cements. Dent Mater 2009; 25:1104-1108.

27. Mazzitelli C, Monticelli F, Toledano M, Ferrari M, Osorio R. Dentin treatment effects on the bonding performance of selfadhesive resin cements. Eur J Oral Sci 2010; 118:80-86.

28. Attia A, Kern M. Influence of cyclic loading and luting agents on the fracture load of two all-ceramic crown systems. J Prosthet Dent 2004; 92:551-556.

29. Attia A, Abdelaziz KM, Freitag S, Kern M. Fracture load of composite resin and feldspathic all-ceramic CAD/CAM crowns. J Prosthet Dent 2006; 95:117-123.

30. Attia A. Influence of surface treatment and cyclic loading on the durability of repaired all-ceramic crowns. J Appl Oral Sci 2010; 18:194-200.

31. Chen HY, Hickel R, Setcos JC, Kunzelmann KH. Effects of surface finish and fatigue testing on the fracture strength of CAD-CAM and pressed-ceramic crowns. J Prosthet Dent 1999; 82:468-475.

32. Valjakova EB, Grozdanov A, Guguvcevski L, Stevkovska VK, Kapusevska B, et al. Acid Etching as Surface Treatment Method for Luting of Glass-Ceramic Restorations, part 1: Acids, Application Protocol and Etching Effectiveness. J Med Sci. 2018; 6:568-573. 
33. Meng X, Yoshida K, Taira Y, Kamada K, Luo X. Effect of siloxane quantity and ph of silane coupling agents and contact angle of resin bonding agent on bond durability of resin cements to machinable ceramic. J Adhes Dent 2011; 13:71-78.

34. Addison O, Marquis PM, Fleming GJ. The impact of hydrofluoric acid surface treatments on the performance of a porcelain laminate restorative material. Dent Mater 2007; 23:461-469.

35. Hooshmand T, Parvizi S, Keshvad A. Effect of surface acid etching on the biaxial flexural strength of two hot-pressed glass ceramics. J Prosthodont 2008; 17:415-424.

36. Zogheib LV, Bona AD, Kimpara ET, McCabe JF. Effect of hydrofluoric acid etching duration on the roughness and flexural strength of a lithium disilicate-based glass ceramic. Braz Dent J 2011; 22:45-50.

37. Venturini AB, Prochnow C, May LG, Bottino MC, Valandro LF. Influence of hydrofluoric acid concentration on the flexural strength of a feldspathic ceramic. J Mech Behav Biomed Mater 2015; 48:241-249.

38. Ozcan M, Allahbeickaraghi A, Dündar M. Possible hazardous effects of hydrofluoric acid and recommendations for treatment approach: a review. Clin Oral Investig 2012; 16:15-23.

39. Xiaoping L, Dongfeng R, Silikas N. Effect of etching time and resin bond on the flexural strength of IPS e.max Press glass ceramic. Dent Mater 2014; 30:e330-336.

40. Venturini AB, Prochnow C, May LG, Kleverlaan CJ, Valandro LF. Fatigue failure load of feldspathic ceramic crowns after hydrofluoric acid etching at different concentrations. J Prosthet Dent 2018; 119:278-285.

41. Scherer MM, Prochnowa C, Venturini AB, Pereira GKR, Burgoc TAL, Rippe MP, Valandro LF. Fatigue failure load of an adhesively-cemented lithium disilicate glassceramic: Conventional ceramic etching vs etch \& prime one-step primer. Dent Mater. 2018; 34:1134-1143.

42. Siqueira FS, Alessi RS, Cardenas AF, Kose C, Souza Pinto SC, Bandeca MC, et al. New single-bottle ceramic primer: 6-month case report and laboratory performance. J Contemp Dent Pract 2016; 17:1033-1039.
43. El-Damanhoury HM, Gaintantzopoulou MD. Self-etching ceramic primer versus hydrofluoric acid etching: etching efficacy and bonding performance. J Prosthodont Res 2018; 62:75-83.

44. Wille S, Lehmann F, Kern M. Durability of resin bonding to lithium disilicate and zirconia ceramic using a selfetching primer. J Adhes Dent 2017; 19:491-496.

45. Prado M, Prochnow C, Marchionatti AME, Baldissara P, Valandro LF, Wandscher VF. Ceramic Surface Treatment with a Single-component Primer: Resin Adhesion to Glass Ceramics. J Adhes Dent. 2018; 20:99-105.

46. Attia A, Abdelaziz KM, Freltag S, Kern M. Frcture load of composite resin and feldspathic all-ceramic CAD/CAM crowns. J Prosthet Dent 2006; 95:117-123.

47. Chaves CAL, de Melo RM, Passos SP, Camargo FP, Bottino MA, Balducci I. Bond strength durability of self-etching adhesives and resin cements to dentin. J Appl Oral Sci 2009; 17:155-160.

48. Zhang C, Degrange M. Shear bond strengths of self-adhesive luting resins fixing dentine to different restorative materials. J Biomater Sci Polym Ed 2010; 21:593-608.

49. Vlotti RG, Kasaz A, Pena CE, Alexandre RS, Arrais CA, Reis AF. Microtensile bond strength of new self-adhesive luting agents and conventional multistep systems. J Prosthet Dent 2009; 102:306-312.

50. Simões TC, Rubim MG, de Carvalho RV, de Sá ATG, Berger SB, Torres WAM. Effect of Polyacrylic Acid Conditioning on the Longevity of Bonding of Self - Adhesive Resin Cement to Dentin. J Health Sci 2018;20:100-105.

51. Pavan S, dos Santos PH, Berger S, Bedran-Russo AK. The effect of dentin pretreatment on microtensile bond strength of self-adhhesive resin cements. . J Prosthet Dent 2010; 104:258-264.

52. Brunzel S, Yang B, Wolfart S, Kern M. Tensile bond strength of a so-called self-adhesive luting resin cement to dentin. J Adhes Dent 2012; 12:143-150.

53. Cerqueira LAC, Costa AR, Spohr AM, Miyashita E, Miranzi BAS, et al. Effect of Dentin Preparation Mode on the Bond Strength Between Human Dentin and Different Resin Cements. Braz Dent J 2018; 29: 268-274. 